\title{
Automatic control of motors through Simocode pro, and its effect on the performance of the process of filling and dispensing of chemical inputs
}

\author{
Omar Chamorro-Atalaya ${ }^{1}$, Augusto Sanchez-Ayte ${ }^{2}$, Carlos Dávila-Ignacio ${ }^{3}$, Orlando Ortega-Galicio $^{4}$, \\ Nestor Alvarado-Bravo ${ }^{5}$, Almintor Torres-Quiroz ${ }^{6}$, Florcita Aldana-Trejo ${ }^{7}$ \\ ${ }^{1-4}$ Faculty of Engineering and Management, National Technological University of Lima Sur, Lima, Perú \\ ${ }^{5,6}$ Faculty of Chemical Engineering and Faculty of Economic Sciences, University National of Callao, Callao, Perú \\ ${ }^{7}$ Faculty of Economic Sciencies, Federico Villareal National University, Lima, Perú
}

\begin{abstract}
Article Info
Article history:

Received Apr 3, 2021

Revised Jun 2, 2021

Accepted Jun 10, 2021

Keywords:

Automatic control

Dispatch process

Engines

Performance

ABSTRACT

This article aims to describe the design of an automatic control system for the automated management of motor drives through Simocode pro; and determine the effect from the quantitative point of view on the performance of the filling and dispatch process of chemical inputs from the perspective of dispatch time and the amount of input spilled in the tank filling stage. For this, the programming of the programmable logic controller was carried out using the simatic step 7 software, then the distributed control system (DCS Siemens S410) was programmed, using the PCS7 V8.1 software, where the control logic and simocode pro integration is carried out through the profibus protocol, which is monitored from an human-machine interface (HMI) interface. Once the control system was implemented, it was possible to reduce the operating time from 60 minutes on average to 35 minutes, which reflects an improvement of $41.66 \%$; this in turn generates an increase in the number of tank filling by $62.84 \%$. Likewise, it is possible to reduce the amount of chemical inputs spilled in the filling stage; this improvement represents $88.60 \%$.
\end{abstract}

This is an open access article under the CC BY-SA license.

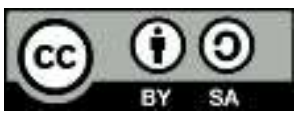

Corresponding Author:

Omar Chamorro-Atalaya

National Technological University of Lima Sur

Jr. Los Damascos, Los Olivos, Lima, Perú

Email: ochamorro@untels.edu.pe

\section{INTRODUCTION}

Most organizations have many factors to be able to carry out the processes and satisfy the market demand [1]. Among the most important factors are: human resources, capital, technology and raw materials [2]. Thus, it is essential to focus on one of these factors and determine its performance so as to achieve the productivity goals of the organization [3]. Although various studies have been carried out on the measurement of performance in operations [4], the emphasis on measuring this indicator due to the technological factor has not been very developed [5]. Nowadays companies must place special emphasis on investing in technology in order to increase their performance, which is closely related to the productivity of a company [6].

In a globalized world, organizations or companies require the continuous implementation of technologies in order to meet the demands of their customers in terms of demand and product quality [7], this because we are in a totally competitive world [8]. In this regard, many companies lack technological infrastructure, which is why they are not increasing their productivity or performance [9]. In relation to the 
above, it would be important to specify what the term productivity means; In this regard [10], it is defined as the degree of performance with which the available resources are used in order to achieve the predetermined objectives.

Today automation is a significant part of the industry [11], its use implies continuous improvement in production processes in an organization [12]. It is under this context that the importance of control systems in industrial processes is highlighted [13]; the current trend regarding the use of control systems is closely linked to guaranteeing the optimal functioning of the equipment and components that are part of the production process [14]. Another aspect to consider when referring to the performance of a production process is the time in which the machines are in operation without showing failures [15], the fact is that the control of the parameters of an industrial process implies a crucial and rigorous activity [16], which must be developed with the highest degree of precision possible [17], since the performance of the process depends on the control, monitoring and supervision of the evolution of the controlled variable with respect to the reference value or set point [18].

Advances with respect to automated control systems are aimed at improving the management of the elements that allow the control of the crucial variables of the production process [19]. Automated management systems for the operation of work organs allow to improve the life cycle of the machines of the productive processes, guaranteeing to improve the productivity of the organizations [20]. Simocode pro is a flexible and modular motor management system [21], which optimizes the management between the process control and the motor bypass [22], increasing the availability of the working organs in the industrial process [23]. This device allows to achieve an automation with integral protection for motors that are part of the production process [24]. Now if we take into account that the companies that have processes related to the dispatch of chemical inputs, contain too many elements that influence in reducing the performance of the system [25].

It is necessary that these organizations be at the forefront of the technology of supervision, control and data acquisition [26]. Given the lack of technological tools to help control the process, they would lead to losses, due to the lack of precision in filling the tares of the trucks that distribute the chemical inputs [27], as well as the delay in dispatch time, relevant aspects that influence the performance of the production process [28]. In this sense, this article aims to describe the design of an automated management system for the drive of motors through Simocode Pro, and to determine the effect from a quantitative point of view on the performance of the process of filling and dispatch of supplies chemicals from the perspective of dispatch time and the amount of input spilled in the tank tank filling stage. It is important to specify that this scientific article is an extension of the results and findings obtained in [29].

\section{VALIDATION OF THE DATA COLLECTED}

\subsection{Data collection}

The data collection was carried out through the observation technique, and the documentary analysis. This is due to the fact that the solution proposal implied the development of a data supervision, acquisition and control system (SCADA), with which it was possible to obtain historical reports regarding the indicators under analysis. However, it is necessary to highlight that before the implementation of the SCADA system, that is, when the stage of filling and dispatching the chemical input (sulfuric acid), responded to a manual process itself, the analysis of documents from previous years was used, working in the quality control area. In addition, in Figure 1, the scheme of the research design used in this research is specified, having as a reference, the purpose of this research, which is to obtain the effect of the proposed solution on the performance of the system, from the perspective of the indicators dispatch time and quantity of input spilled in the filling stage.

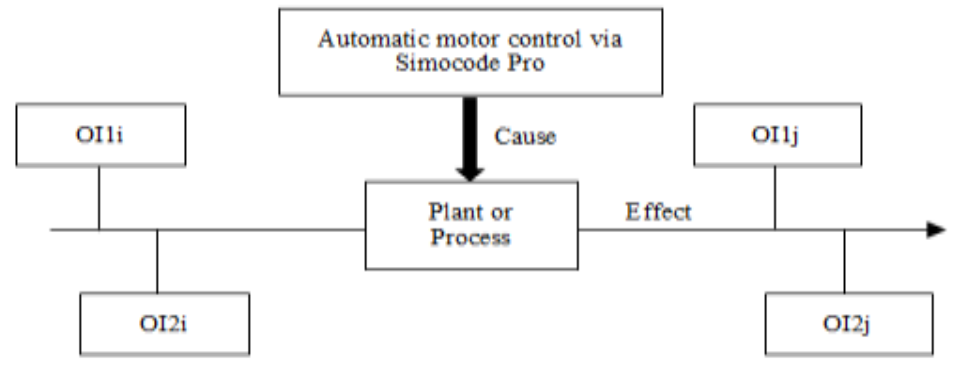

Figure 1. Data collection design scheme 
Where OI1i, represents the observation of indicator 1 (dispatch time) and OI2i, represents the observation of indicator 2 (amount of input spilled or in the filling stage), before the application of the proposed solution. While OI $1 \mathrm{j}$ represents the observation of indicator 1 (dispatch time) and OI $2 \mathrm{j}$ the observation of indicator 2 (amount of input spilled in the filling stage), after the application of the proposed solution. It is specified that both the " $\mathrm{i}$ " and " $\mathrm{j}$ " indices range from 1 to 12 , due to the fact that the data collection is longitudinal, that is, the data is collected on a monthly basis for one year.

\subsection{Reliability analysis}

In order to establish the degree of reliability of the data collected, Table 1 and Table 2 show the results obtained from Crombach's Alpha, using the statistical software SPSS version 25; the analysis is shown by indicator, highlighting both indicators under study and intervening indicators. The Cronbach's Alpha value is also specified on average in the average of the data collected in the two analyzed scenarios, that is, before and after the implementation of automatic motor control through simocode pro. Based on the results obtained, it is stated that the level of reliability of the data collected is high.

Table 1. Cronbach's alpha of the manual process data

\begin{tabular}{lc}
\hline \multicolumn{1}{c}{ Indicators in analysis } & Cronbach's alpha \\
\hline Dispatch time (min) & 0.902 \\
Stop time for overflow (min) & 0.901 \\
Number of tanks filled & 0.900 \\
Quantity of chemical inputs dispatched $(\mathrm{kg})$ & 0.902 \\
Amount of chemical inputs lost for overflow (kg) & 0.900 \\
Average Cronbach's alpha & 0.901 \\
\hline
\end{tabular}

Table 2. Cronbach's alpha of the automatic process data

\begin{tabular}{lc}
\hline \multicolumn{1}{c}{ Indicators in analysis } & Cronbach's alpha \\
\hline Dispatch time (min) & 0.943 \\
Stop time for overflow (min) & 0.944 \\
Number of tanks filled & 0.922 \\
Quantity of chemical inputs dispatched (kg) & 0.911 \\
Amount of chemical inputs lost for overflow (kg) & 0.932 \\
Average Cronbach's alpha & 0.930 \\
\hline
\end{tabular}

\subsection{Normal distribution analysis}

Obtained the reliability results and in order to show the level of distribution of those collected with respect to the indicators in analysis, then I proceed to show in Table 3, the results of the normality test by means of the Shapiro Wilk test, obtained by the use of the statistical software SPSS version 25. It should be noted that since the data were collected in a period of one year, the sample presented 12 results, therefore it is specified that the Shapiro Wilk test will be used, which is used for samples less than 50. It should be noted that this test affirms that there is a distribution of the data, only if the bilateral significance (sig.) is greater than the $\alpha$ (significance level), which is equal to 0.05 . According to what was obtained, it is affirmed that the bilateral significance of the data in all the indicators is greater than 0.05 , therefore it is sustained that there is normality in the collected data.

Table 3. Normality test of the data using Shapiro-Wilk

\begin{tabular}{lcc}
\hline \multicolumn{1}{c}{ Indicadores en análisis } & gl & Significance \\
\hline Dispatch time (min) & 12 & 0.640 \\
Stop time for overflow (min) & 12 & 0.516 \\
Number of tanks filled & 12 & 0.620 \\
Quantity of chemical inputs dispatched $(\mathrm{kg})$ & 12 & 0.850 \\
Amount of chemical inputs lost for overflow $(\mathrm{kg})$ & 12 & 0.613 \\
\hline
\end{tabular}

\section{PROCEDURE}

\subsection{Description of the automated process}

In Figure 2, the flow diagram of the process of filling and dispatching the tank containing the chemical input is observed, for which it was established that the dispatch operation of the tank can be in manual or automatic mode, so that it can operate the system in one of these two modes, the equipment must be enabled (motors). If not, the operator must go to the command and control room (CCM) and enable the main switch. Subsequently we access the WinCC monitoring system. 
The supervisory system for the dispatch of chemical input tanks (sulfuric acid) has two stations, which are located in the balance control room, which are permanently used, under strict control and monitoring of the two stages under study. The software used is PCS7 Version 8.1 and data collection is done through a Siemens S7-400 PLC, connected to the supervisor system through an Ethernet control network. The graphical interface allows additionally to control and monitoring, also to turn on, turn off equipment and acknowledge alarms. As well as through connection to a database of all process variables in which analog and discrete signals are identified.

Figure 3 shows the P\&ID diagram of all the electronic instrumentation in the field, close to the process of filling and dispatching the sulfuric acid from the tank. It can be seen that during the closing of the actuator the beacon and intermittent siren will be activated to account for the end of the attention. If during the attention the overfill sensor is activated, the beacon and siren will be activated permanently for 45 seconds. The controlled valves will remain open at $100 \%$ while the cistern tank is filled, until $300 \mathrm{~kg}$ after filling is complete, the proportional closure will begin as indicated. When $300 \mathrm{~kg}$ is missing, the valve will be at $50 \%$, when $150 \mathrm{~kg}$ is missing, the valve will be at $25 \%$, when $75 \%$ is missing, the valve will be at $15 \%$ and finally when $25 \mathrm{~kg}$ is missing, the valve will be at $10 \%$. Likewise, a time delay has been configured in the controller that will protect the dispatch line from overpressure. In other words, once the pump is started, the control system must receive confirmation of the valve opening, if the valve remains open for no more than 3 seconds, the control system will close it. Enabling the pump automatically enables the control valve corresponding to the scale where the delivery will take place.

It is under this context that the motor control system is described through the Siemens Simocode pro; In Figure 4, the architecture of the control circuit for the management of engines that participate in the process of filling and dispatching tanks through the Simocode pro is shown. It is important to specify that in the figure shown, In 1 is the confirmation of the selection in automatic, while the input In2, is the equipment start-up confirmation. It must be taken into account that the start-up with the Simocode pro of the pumps will be linked by the profibus industrial communication network, to be monitored later from WinCC.

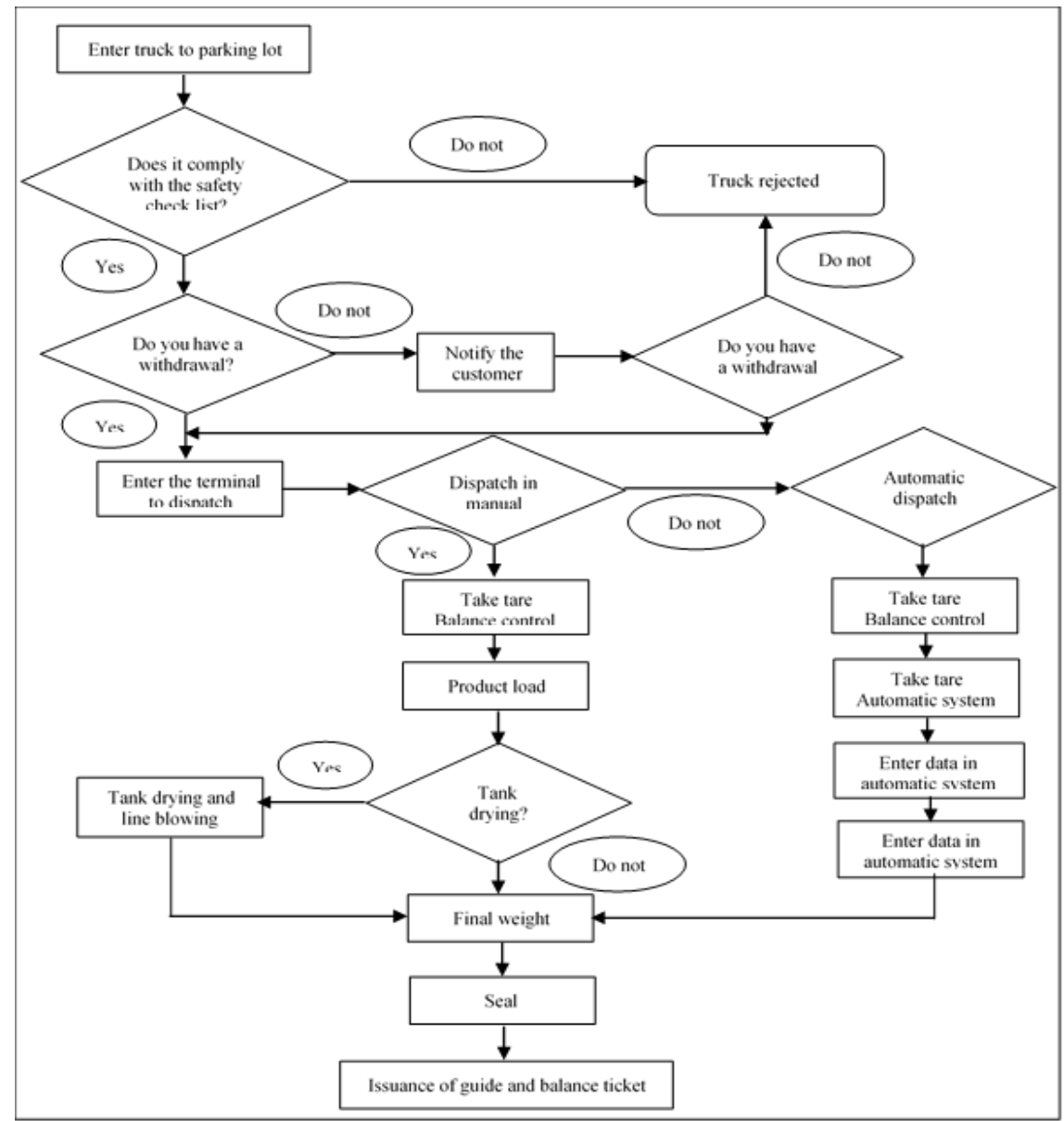

Figure 2. Flow diagram of the tank filling and dispatch process 


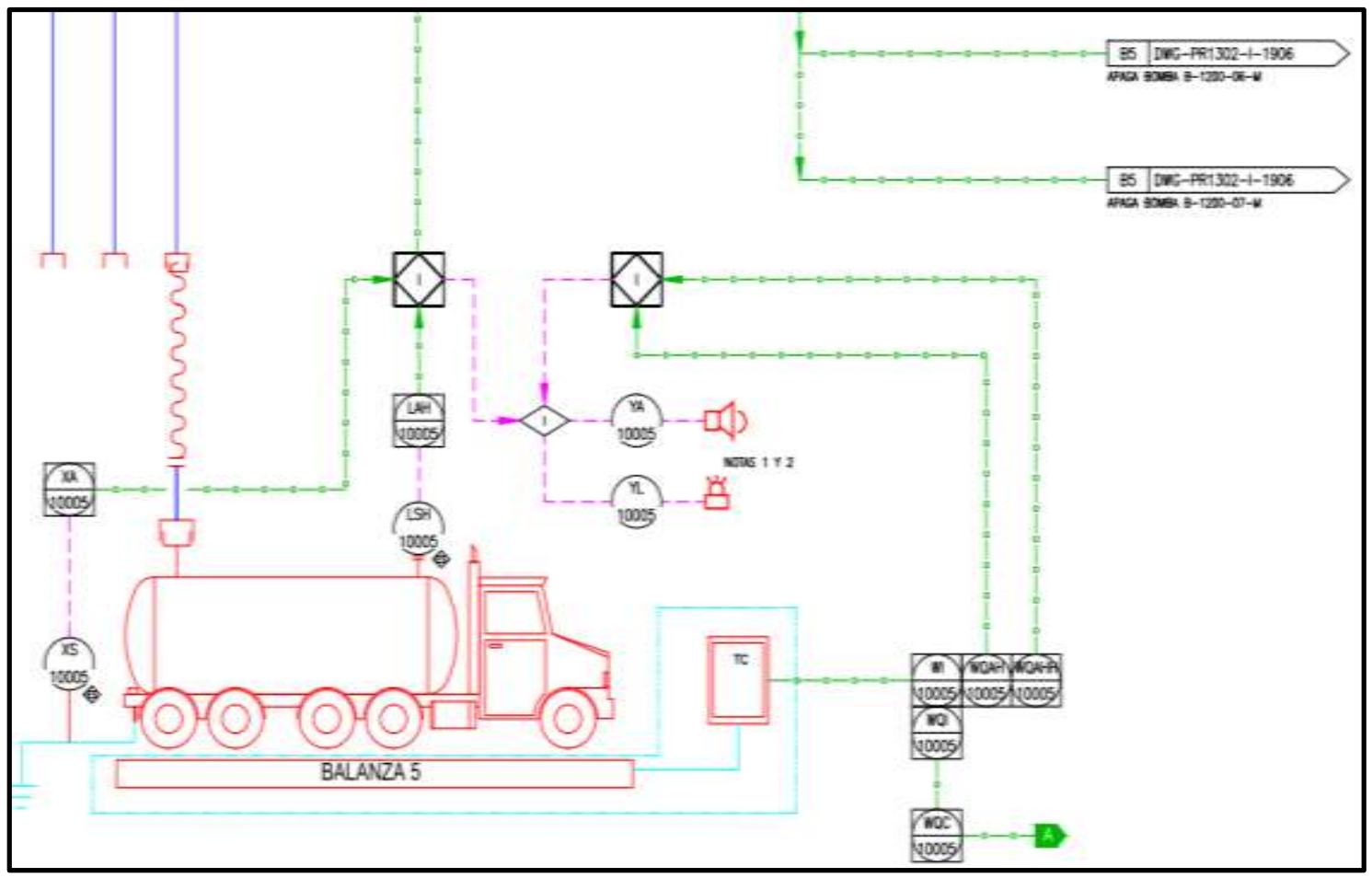

Figure 3. P\&ID of the control circuit for engine management through Simocode pro

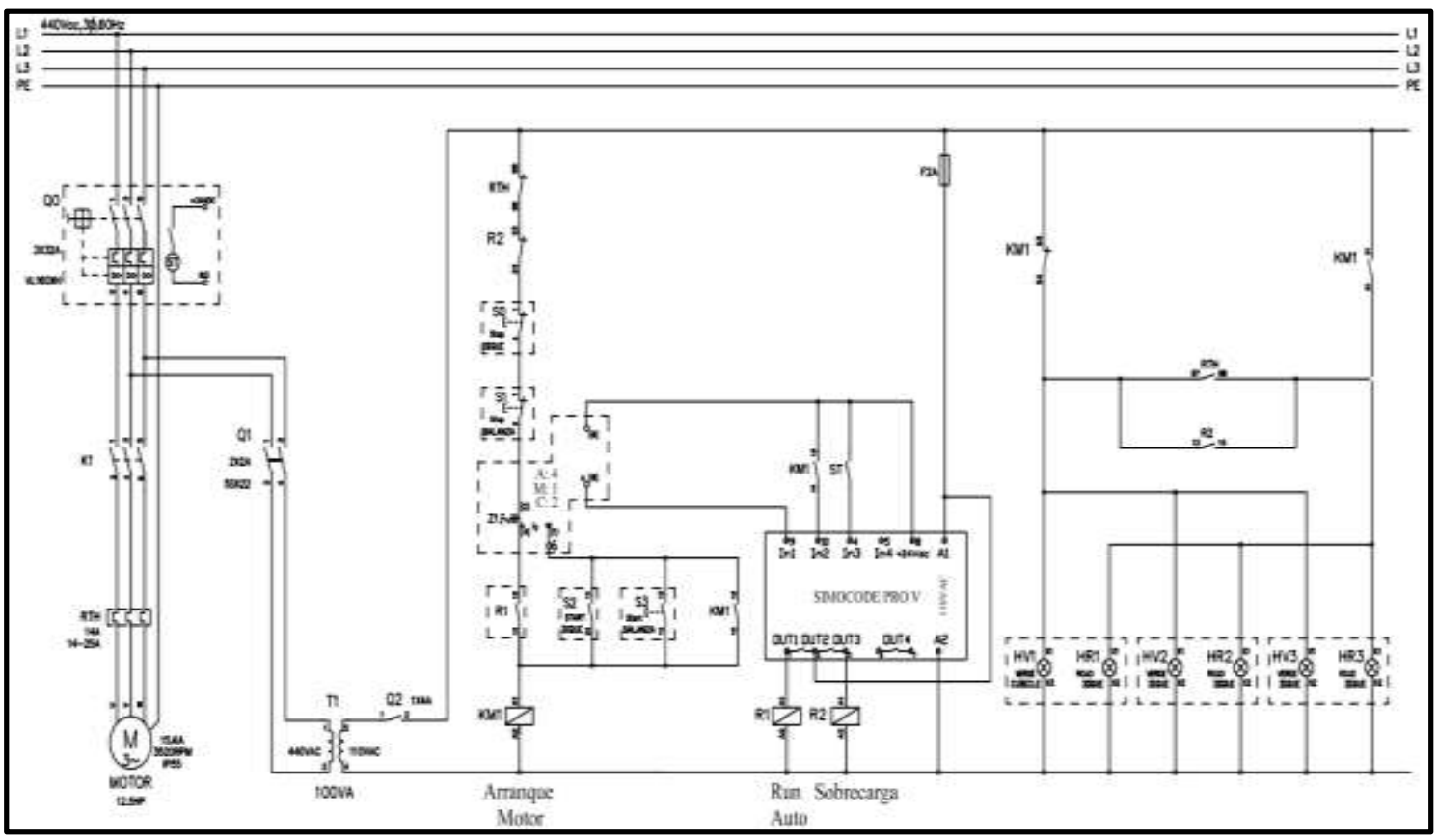

Figure 4. Control circuit for engine management through Simocode Pro

Having fixed the architecture of the control system and establishing the components to be used, next, we proceed to show the programming of the programmable logic controller using the SIMATIC STEP 7 Software, and then carry out the programming of the distributed control system (DCS SIEMENS S410), using the PCS7 V8.1 Software, where the control logic is configured, as shown in Figure 5 the hardware configuration of the industrial network and in Figure 6 the integration of the Simocode pro through the profibus protocol. 


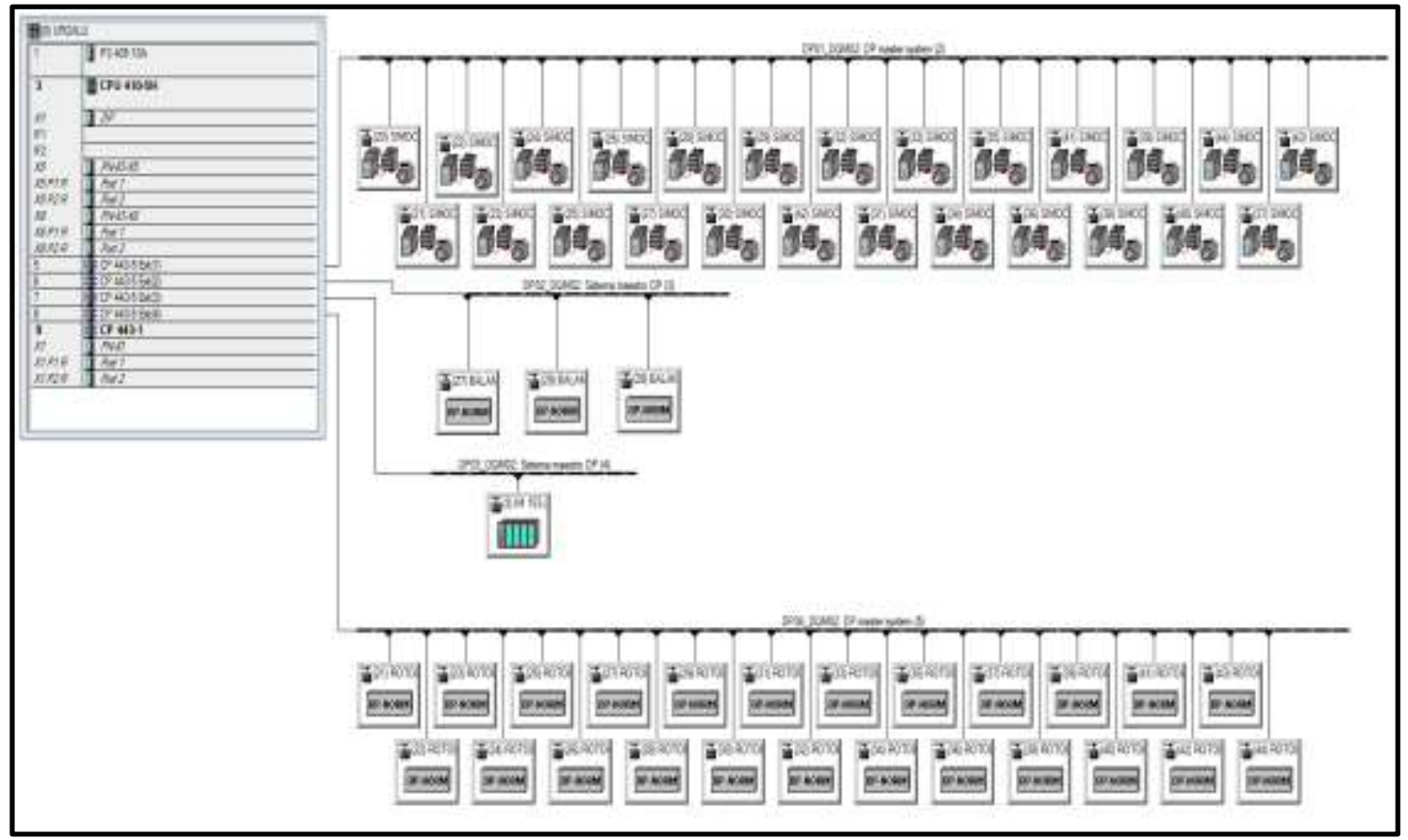

Figure 5. Industrial network hardware configuration

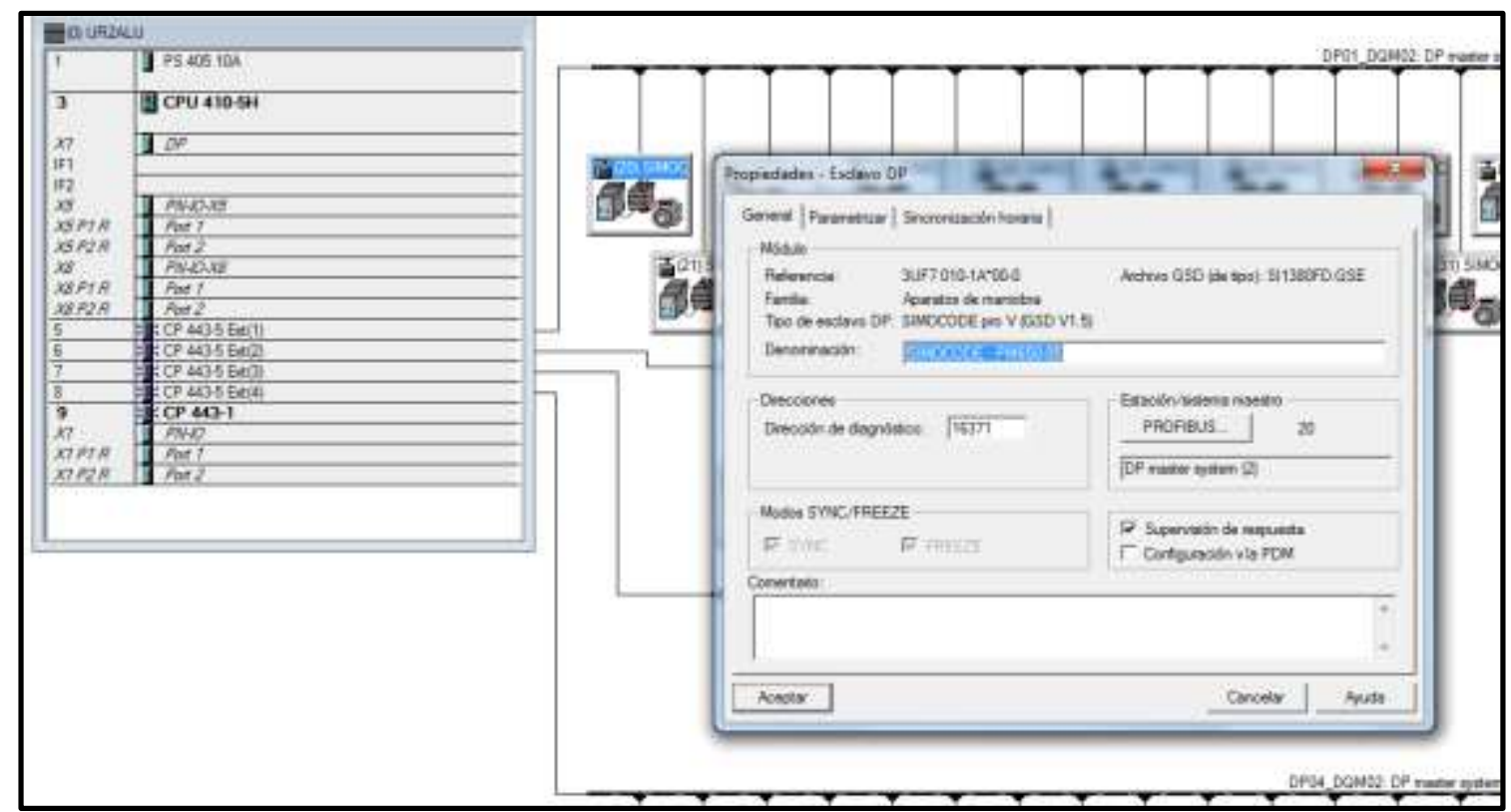

Figure 6. Simocode pro integration through profibus protocol

\section{RESULTS AND DISCUSSION}

\subsection{Results}

Figure 7 shows the results obtained in relation to the effect that automation has had on the dispatch time of chemical inputs, as can be seen there is an improvement in this indicator, which represents an average of $1.6 \%$ in percentage terms. More specifically, the automatic dispatch process lasts for 35 minutes per operation, while with the manual process this time ranged from 55 to 65 minutes, before this the improvement is $41.66 \%$. Now regarding the total dispatch time it can be indicated that in a daily workday it has decreased from 464 minutes to 455 minutes, in percentage terms it represents $1.94 \%$. Although it may seem like a small improvement value, it becomes relevant, when it is related to the dispatch time with the amount of chemical inputs dispatched, this can be seen in Figure 8. 


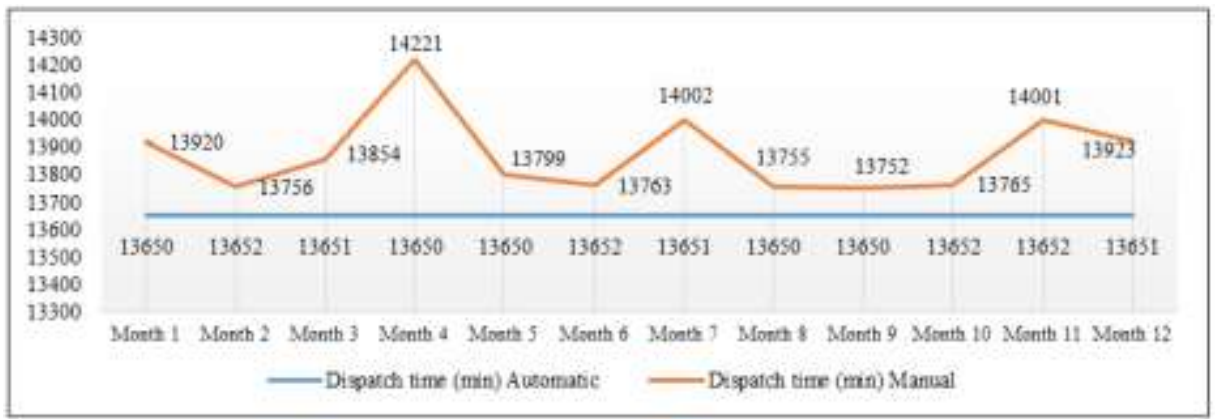

Figure 7. Annual comparative analysis of dispatch time (min)

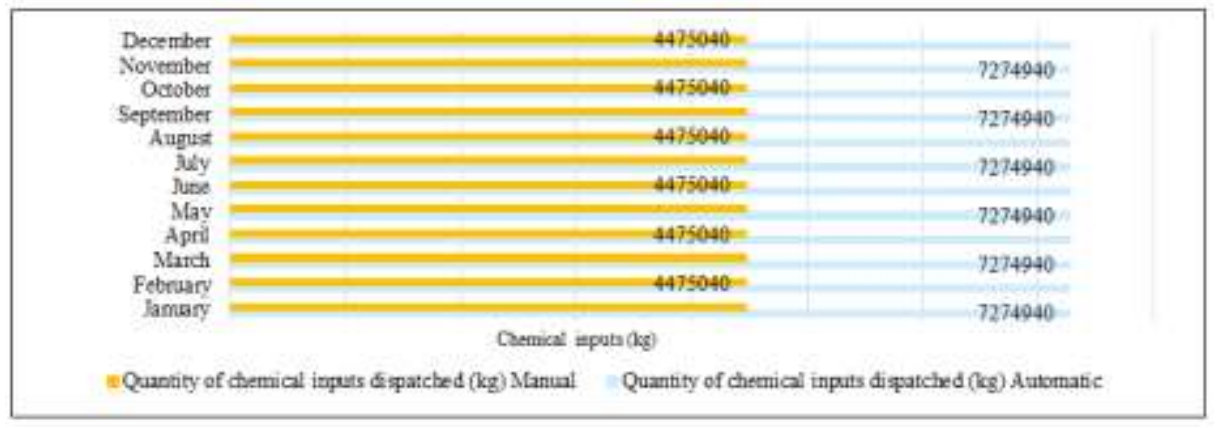

Figure 8. Annual comparative analysis of the quantity of chemical inputs dispatched (min)

As can be seen, once the automatic process has been applied, a positive effect has been generated in the quantity of chemical inputs dispatched, because the annual quantity has improved by $62.56 \%$, due to the fact that, before a total of $53,700,480.00 \mathrm{~kg}$ annually and now with a shorter time, with an improvement of $1.6 \%$, a total of $87,299,280.00 \mathrm{~kg}$ is shipped per year. Something important to note is that although, in both automatic and manual processes, the amount of chemical inputs per tank continues to be $18,646.00 \mathrm{~kg}$, the increase in this indicator has been generated by the decrease in dispatch time, this allows that in the day a greater number of tanks is filled, therefore, the amount of chemical inputs dispatched increases from $149,168.00 \mathrm{~kg}$ to $242,398.00 \mathrm{~kg}$ per day.

As indicated, the variation in the quantity of chemical inputs $(\mathrm{kg})$ dispatched is directly related to the improvement of dispatch time, this has a positive influence, since a greater number of tanks is filled during the day. This annual improvement is due to the fact that with the manual process a total of 2,874 tanks were filled, while with the automatic the number has increased to 4,680, which represents an improvement of $62.84 \%$. Specifically, with the automatic process per day, a total of 13 tanks are filled in 455 minutes, which previously was a total of 8 tanks in a time of 464 minutes.

Likewise, the increase in the number of tanks and the optimization of the dispatch time, is generated and is related to the decrease in the downtime for each operation per day of the dispatch process, which occurred when the chemical input was overflowing of the cistern tank due to the lack of precision and the delay in closing the valves, which were operated manually. Because of what was described for each operation in the manual process, it took about 12 to 20 minutes for the other tank to be able to go up to the scale, which, on the day, this stop time reached an average of 144 minutes. A totally different scenario is generated when the automation is applied, where the stop time per operation is reduced to 7 minutes, this time is the one that takes from the closing of the filling valve to the rise of the next scale, which in the day represents a total of 91 minutes of stoppage of the automatic process; As a percentage, it can be noted that there is an improvement of $36.8 \%$ on the day.

Thus, an annual improvement in the stoppage time in the dispatch process was also determined, this when the automation was implemented, according to the data collected, when it was operated manually, there was a total of 4852 minutes where production stopped due to some failure or overflow of the tank of the cisterns, now this indicator decreased to 2730 minutes, this represents an annual improvement of $42.63 \%$; as there is less time for process stoppages, it generates higher performance.

In addition, a positive annual variation was determined in the amount of chemical inputs wasted due to the overflow of the tank tanks, this when the automation was implemented. According to the data collected, when it was operated manually, there was a total of $48,160.00 \mathrm{~kg}$ of chemical inputs that were lost manually, due to the overflow of the tank of the cisterns or some failure of the system, now when the automation was applied, this 
indicator decreased at $5,493.00 \mathrm{~kg}$ of waste per year, this represents an annual improvement of $88.60 \%$. Being more specific, on the day with the automatic process per operation there is on average a possibility of spillage of 1 to $1.5 \mathrm{~kg}$, while with the manual process this amount could reach up to $20 \mathrm{~kg}$ per operation; This variation means a decrease in average from $129 \mathrm{~kg}$ to $15.7 \mathrm{~kg}$ of waste of chemical inputs per day, which is equal to an improvement of $87.83 \%$.

\subsection{Discussions}

Regarding the dispatch time of chemical inputs, an improvement of this indicator of $1.6 \%$ is achieved; This has generated a positive annual effect of $62.56 \%$ in the quantity of chemical supplies dispatched, which represents an improvement of $62.84 \%$ in the increase in the number of filled tanks. These results agree with what was obtained in [20], where it is pointed out that when the automation process is carried out, it is evident how the production line improves in terms of control and manipulation of the immersion times of the product; Regarding the number of production, $1000 \mathrm{~kg}$ were produced on the manual line and by adapting the automation, $3000 \mathrm{~kg}$ are produced in a shift with a single operator without any physical or mental wear. Similarly in [21] it is pointed out that, by implementing the automation system in the hydrochloric acid dispatch process, it is possible to dispatch a greater quantity of hydrochloric acid safely and with fewer operators, in this way the system increases its performance by $75 \%$.

Regarding the amount of chemical inputs spilled in the filling stage, an annual improvement of $88.60 \%$ is achieved. Likewise, with this, it is possible to reduce the stop time of the process due to the spillage of chemical inputs by $42.63 \%$. In view of this, in [21] it is pointed out that by making the automated system by programming the Siemens CPU 1214C PLC and the KTP1000 HMI, it was possible to define exactly the amount of acid to be dispensed through manual or automatic control, thereby reducing amount of wasted hydrochloric acid; This not only protects the operator but also reflects a significant economic saving.

\section{CONCLUSION}

Through the automatic control system, it was possible to improve the dispatch time of chemical supplies, reducing the operating time from 60 minutes on average to 35 minutes, which reflects an improvement of $41.66 \%$. The improvement of the process generates an increase in the number of tank filling by $62.84 \%$. In this sense, it is recommended to train the personnel who will be in charge of the operation of the automated management system, in order to be able to provide them with the necessary scope of the operation of the system from the HMI and attend to the alarms that may arise; as well as that they are able to connect online with the PLC so that in the future modifications of the system can be made according to the requirements of the company. Thus, it is also concluded that through this proposed solution, it is possible to reduce the amount of chemical inputs spilled in the filling stage; this improvement represents $88.60 \%$. This variation means a decrease on average from $129 \mathrm{~kg}$ to $15.7 \mathrm{~kg}$ of waste of chemical inputs per day. For better system performance, it is recommended to perform physical tests twice a year with the appropriate instrumentation, following the procedures performed in the simulations, in order to prevent failures or breakdowns that affect the safety of the system.

\section{REFERENCES}

[1] T. F.Herrera, E. D. Granadillo and J. M. Gómez, "Productivity and its factors: Impact on Organizational Improvement," Journal Dimensión Empresarial, vol. 16, no.1, pp. 47-60, Nov. 2018, doi: 10.15665/dem.v16i1.1897.

[2] G. M. Hoyos, G. M Montalvo and M. V. Coronado, "Improving productivity by a management system based on lean six sigma in the production process of pallets in the company maderera", Engineering Magazine, vol. 5, no. 2, pp. 343-350, Jan. 2018, doi: 10.26495/icti.v8i1.

[3] K. E. Flores, J. T. Barahona, and M. V. Coronado, "Management by Processes to Increase Productivity in the Company Commerce Industry and Services GMV E. I. R. L.," Scientific Journal of Engineering: Sciences, Technology and Innovation, vol. 5, no.1, pp. 1-11, Oct. 2017, doi: 10.26495/icti.v7i1.1355.

[4] K. Salas-Navarro, J. A. Meza, T. Obredor-Baldovino, and N. Mercado-Caruso. "Evaluation of the Supply Chain to Improve Competitiveness and Productivity in the Metalworking Sector in Barranquilla, Colombia", Technology Information Magazine, vol. 30, no. 2, pp. 25-32, Jul. 2019, doi: 10.4067/S0718-07642019000200025.

[5] N. Montes-Valencia, "The Chemical Industry: Importance and Challenges", J. Lampsakos, vol. 14, no. 2, pp.72-85, 2016.

[6] E. C. Nieto, "Manufacturing and Automation in Spain Manufactura y automatización," Ingeniería e Investigación, vol. 26, no. 3, pp. 120-128, 2006.

[7] Hofman, M. Mas, C. Aravena, and J. Fernández, "Economic growth and productivity in Latin America. The LA-KLEMS project”, Economic perspective magazine, vol. 84, no. 1, pp. 259-306, Nov. 2017, doi: 10.20430/ete.v84i334.302.

[8] D. A. Avecillas, S. N. Acuña, and E. A. Piñero, "The Influence of the Implementation of Information Technologies in the Productivity of Service Companies", Tech. Infor. J., vol. 29, no. 6, pp. 199-212, 2018, doi: 10.4067/S0718-07642018000600199.

[9] D. A. Avecillas, C. P. Lozano, M. B. Ubilla, and C. V. Silva, "Contrasting the Productivity Paradox due to the use of Information Technologies,” Technology Information Journal, vol. 28, no. 1, 171-178, 2017, doi: 10.4067/S0718-07642017000100017. 
[10] F. C. Argumedo, A. V. Montellano, S. N. Tilvaldyev, and D. C. Monroy, "Improvement of Productivity, quality and ergonomics of an assembly operation through Automation," Cultura Científica y Tecnológica, vol. 58, no. 13, pp. 213-223, Jan. 2016.

[11] P. A. Quinteros, B. Y. Miranda, B. Y. Miranda, and K. A. Castillo, "Analysis of the levels of automation of the industrial processes of the company Balsariver Cía. Ltda in Spain Análisis de los niveles de automatización de los procesos industriales de la empresa "Balsariver Cía. Ltda," Journal of Business and entrepreneurial studies, vol. 4, no. 2, pp. 259-265, May. 2020, doi: 10.37956/jbes.v4i2.101.

[12] D. F. Merchán, J. A. Peralta, A. Vazquez-Rodas, L. I. Minchala, and D. Astudillo-Salinas, "Open Source SCADA System for Advanced Monitoring of Industrial Processes," 2017 International Conference on Information Systems and Computer Science (INCISCOS), 2017, pp. 160-165, doi: 10.1109/INCISCOS.2017.9.

[13] M. T. Wollschlaeger, T. K. Sauter, and J. M. Jasperneite, "The future of industrial communication: Automation networks in the era of the internet of things and industry 4.0," IEEE Industrial Electronics Magazine, vol. 11, no. 2, pp. 17-27, Jan. 2017, doi: 10.1109/MIE.2017.2649104.

[14] D. P. Danalaskshmi, S.M. Bugata, and J. B. Kohila, "A control strategy on power quality improvement in consumer side using custom power device," Indonesian Journal of Electrical Engineering and Computer Science (IJEECS), vol. 15, no. 1, pp. 80-87, Jan. 2019, doi: 10.11591/ijeecs.v15.i1.pp80-87.

[15] C. S. Reddy and K. B. Balaji, "A fuzzy-PID controller in shell and tube heat exchanger simulation modeled for temperature control”, Indonesian Journal of Electrical Engineering and Computer Science (IJEECS), vol. 21, no. 3, pp. 1364-1371, Mar. 2021, doi: 10.11591/ijeecs.v21.i3.pp1364-1371.

[16] S. N. Al-Bargothi, G. M. Qaryouti, and Q. M. Jaber, "Speed control of DC motor using conventional and adaptive PID controllers", Indonesian Journal of Electrical Engineering and Computer Science (IJEECS), vol. 16, no. 3, pp. 1221-1228, Dec. 2019, doi: 10.11591/ijeecs.v16.i3.pp1221-1228.

[17] P. P. Gakhar and M. M. Gupta, "A novel control strategy for power quality improvement in grid-connected solar photovoltaic system," Indonesian Journal of Electrical Engineering and Computer Science (IJEECS), vol. 15, no. 3, pp. 1264-1272, Sep. 2019, doi: 10.11591/ijeecs.v15.i3.pp1264-1272.

[18] F. S. Alhhafaji, W. H. Hasan, M. M. Isa, and N. N. Sulaiman, "A response time reduction for DC motor controller using SISO technique", Indonesian Journal of Electrical Engineering and Computer Science (IJEECS), vol. 17, no. 2, pp. 895-906, Feb. 2020, doi: 10.11591/ijeecs.v17.i2.pp895-906.

[19] K. R. Wagiman, M. N. Bdullah, M. Y.Hassan, and N. M. Radzi, "A review on sensing-based strategies of interior lighting control system and their performance in commercial buildings," Indonesian Journal of Electrical Engineering and Computer Science (IJEECS), vol. 16, pp. 208-215, 2019, doi: 10.11591/ijeecs.v16.i1.pp208-215.

[20] S. Arunkumar and S. Thangavel, "A Review Paper on Torque Ripple Reduction in Brushless DC Motor Drives with Different Multilevel Inverter Topology," Indonesian Journal of Electrical Engineering and Computer Science (IJEECS), vol.13, no. 1, pp. 65-75, Jan. 2015, doi: 10.11591/telkomnika.v13i1.6904.

[21] M. M. Barzegaran and S. S. Tajvidi, "A Robust Control with the Combination of Fuzzy and SMC to Stabilize the Power System," Indonesian Journal of Electrical Engineering and Computer Science (IJEECS), vol. 4, no. 2, pp. 341-353, Nov. 2016, doi: 10.11591/ijeecs.v4.i2.pp341-353.

[22] M. F. Farhan, N. S. A. Shukor, M. A. Ahmad, M. H. Suid, M. R. Ghazali, and M. F. M. Jusof, "A simplify fuzzy logic controller design based safe experimentation dynamics for Pantograph-Cateary system," Indonesian Journal of Electrical Engineering and Computer Science (IJEECS), vol. 14, no. 2, pp. 903-911, 2019, doi: 10.11591/ ijeecs.v14.i2.pp903-911.

[23] G. G. Joshi and A. J. Pinto, "ANFIS controller for vector control of three phase induction motor," Indonesian Journal of Electrical Engineering and Computer Science (IJEECS), vol. 19, no.3, pp.1177-1185, Sep. 2020, doi: 10.11591/ijeecs.v19.i3.pp1177-1185.

[24] N. N. Abdul, N. M. Saad, A. R. Abdullah, M. M. Hassan, M. M. Basir, and N. M. Noor, "Automated Real-time Vision Quality Inspection Monitoring System," Indonesian Journal of Electrical Engineering and Computer Science (IJEECS), vol. 11, no.2, pp. 775-783, Aug. 2018, doi: 10.11591/ ijeecs.v11.i2.pp775-783.

[25] J. E. S. Cerón and M. I. S. Ramón, "Optimization of the Sodium Hypochlorite dispatch processes for a Chemical Production Plant in Guayaquil," Thesis, Faculty of Natural Sciences and Mathematics, Escuela Superior Politécnica del Litoral (ESPOL) Guayaquil, Ecuador, 2010.

[26] Duque-Marin, A. J. Lopez, and A. F. Navas, "Auto-tuning of a PID controller implemented in a PLC using swarm intelligence," Propsective Review, vol. 15, no. 1, pp.35-41, Jan. 2017, doi: doi.org/10.15665/rp.v15i1.679.

[27] J. P. Gonzales and Juan Pablo, "Design and implementation of digital controllers through a data acquisition system," Journal Scientia et Technica, vol. 21, no. 3, pp. 65-74, Oct. 2016.

[28] M. R. Vinothkanna, "Design and Analysis of Motor Control System for Wireless Automation," Journal of Electronics and Informatics, vol. 2, no. 3, pp. 162-167, Jun. 2020, doi: 10.36548/jei.2020.3.002.

[29] O. Chamorro-Atalaya, J. Yataco-Yataco, and D. Arce-Santillan, "Industrial Network for The Control and Supervision of the Acetic acid Dispatch Process, and Its Influence on The Reduction of Chemical Contaminants for Operators," Advances in Science, Tech. and Eng. Systm., J., vol. 5, no. 1, pp. 13-20, 2020, doi: 10.25046/aj050103.

[30] M. A. Chaparro and R. S. Espinel, "Automation of a machine of automation of an electrolytic or electrolytic coating machine," Faculty of Engineering, The Salle University, Bogota, Colombia, 2016.

[31] K. P. Lopez, "Design of an automation system dispatch of hydrochloric acid to improve delivery control on tank trucks for The Company Quimpac S.A. Paramonga Peru-2018," Thesis Master, Faculty of Industrial Engineering, Universidad Nacional de Piura, Peru, 2018. 